\title{
FASES ESTACIONÁRIAS PARA CROMATOGRAFIA LÍQUIDA DE ALTA EFICIÊNCIA EM FASE REVERSA (CLAE-FR) BASEADAS EM SUPERFÍCIES DE ÓXIDOS INORGÂNICOS FUNCIONALIZADOS
}

\author{
Edivan Tonhi, Kenneth E. Collins, Isabel C. S. F. Jardim e Carol H. Collins* \\ Instituto de Química, Universidade Estadual de Campinas, CP 6154, 13083-970 Campinas - SP
}

Recebido em 24/7/01; aceito em 31/10/01

\begin{abstract}
STATIONARY PHASES FOR REVERSED PHASE HIGH PERFORMANCE LIQUID CHROMATOGRAPHY (RP-HPLC) BASED ON FUNCTIONALIZED INORGANIC OXIDE SURFACES. Particles of porous silica or other solvent resistent inorganic oxides can be functionalized by aliphatic (e.g., C-8 or C-18) or other groups to give stationary phases for use in reversed phase HPLC. The functionalization can be done by bonding of individual groups to the surface of the support particles, by producing an organic polymeric film from pre-polymers, or by adsorbing/immobilizing pre-formed polymers on the surfaces. These three types of functionalization are reviewed.
\end{abstract}

Keywords: HPLC; reversed phase; functionalized inorganic oxides.

\section{INTRODUÇÃO}

A Cromatografia Líquida de Alta Eficiência (CLAE) é uma técnica de separação que, em menos de trinta anos, passou a ser um dos métodos analíticos mais utilizados para fins qualitativos e quantitativos. As razões para este crescimento estão relacionadas à sua adaptabilidade para determinações quantitativas com boa sensibilidade, a possibilidade de separar espécies não voláteis e termicamente instáveis, com destaque para a indústria farmacêutica, bem como as suas aplicações em determinações ambientais e em muitos outros campos da ciência, como o da medicina.

Dentro da CLAE, estima-se que mais de $90 \%$ dos laboratórios de análise espalhados pelo mundo utilizam pelo menos um método que aplica a modalidade de CLAE em fase reversa (FR ${ }^{1}$. Sistemas de CLAE-FR consistem de uma fase estacionária de menor polaridade e uma fase móvel de maior polaridade, enquanto a fase normal tem as polaridades invertidas. Estas fases apresentam várias vantagens, tais como: uso de fases móveis menos tóxicas e de menor custo, como metanol e água; fases estacionárias estáveis de muitos tipos diferentes; rápido equilíbrio da coluna após a mudança da fase móvel; facilidade de empregar eluição por gradiente; maior rapidez em análises e boa reprodutibilidade dos tempos de retenção. Além disso, são muito aplicadas à separação de solutos de diferentes polaridades, massas molares e funcionalidades químicas.

O presente trabalho visa revisar as fases estacionárias de CLAEFR com destaque para os desenvolvimentos recentes.

\section{SUPORTES}

Por mais de 30 anos a sílica tem sido o material preferido para a preparação das fases estacionárias para CLAE-FR, sendo que é mecanicamente estável à altas pressões, pode ser facilmente modificada, existe um vasto conhecimento de sua estrutura e suas propriedades e é comercialmente disponível em uma grande variedade de tamanho de partículas, formas e tamanhos de poros.

Por outro lado, as fases baseadas em sílica tendem a serem limitadas em dois aspectos importantes. Um destes aspectos está relaci-

\footnotetext{
*e-mail: chc@iqm.unicamp.br
}

onado à não homogeneidade da sua superfície, que apresenta diferentes tipos de grupos silanóis ${ }^{2,3}$, os quais afetam a funcionalização e, consequentemente, o mecanismo de retenção. Os silanóis (三Si$\mathrm{OH}$ ) são ácidos e podem interagir fortemente com vários tipos de moléculas básicas (fármacos, bio-orgânicos, etc.) e adsorvê-las. Quando a adsorção é reversível, tem-se o problema de picos largos, assimétricos e com cauda, que são difíceis de serem tratados quantitativamente, além de poderem se sobrepor ou interferirem nos picos de outros solutos que eluem com tempos de retenção similares. Muitas vezes, a adsorção pode ser irreversível e os compostos depositados na superfície cromatográfica podem restringir o transporte de massa, bloquear sítios de interação normal e criar sítios ativos não específicos, afetando o desempenho da coluna, podendo até levá-la à deterioração irreversível ${ }^{4}$.

O segundo aspecto é a instabilidade da sílica e das fases estacionárias sintetizadas baseadas em sílica, tanto frente a fases móveis ácidas como básicas. Os grupos silanóis e siloxanos ( $\equiv \mathrm{Si}-\mathrm{O}-\mathrm{Si} \equiv)$ reagem com estas fases móveis, sofrendo dissolução, causando perda da fase estacionária e, eventualmente, colapso da estrutura do leito da coluna ${ }^{5,6}$. Este problema de instabilidade em soluções de $\mathrm{pH}$ bai$\mathrm{xo}^{7}$ ou alto ${ }^{8-10}$ é muito importante em CLAE-FR, sendo que soluções com pH 2,5 ou pH 9,0 são recomendadas ${ }^{11}$ para a análise de diversos compostos contendo, em sua estrutura, grupos ácidos como carboxílicos e fenólicos e básicos como aminas e amidas, tais como os encontrados em, por exemplo, fármacos e pesticidas.

Para evitar o problema de instabilidade da fase estacionária em soluções ácidas ou básicas, existe a possibilidade de substituir a sílica utilizada como suporte. Fases estacionárias com suportes de celulose ou polímeros de estireno-divinilbenzeno ${ }^{12}$ foram as primeiras a serem testadas, mas estas fases apresentam problemas de baixa resistência às altas pressões empregadas em CLAE. Outros suportes utilizados são os óxidos inorgânicos como alumina, titânia e zircônia.

A alumina ${ }^{13-15}$ tem resistência mecânica comparável à sílica e resistência química maior, mas não é disponível comercialmente com tanta variedade. Uma vantagem da utilização da alumina como suporte é a sua estabilidade frente a fases móveis com $\mathrm{pH}$ acima de 12 , podendo separar compostos básicos sem a necessidade de utilizar reagente par-iônico ou supressão iônica. Entretanto, uma desvantagem do seu uso ocorre na separação de ácidos carboxílicos, pois estes compostos se ligam irreversivelmente na sua superfície. Para 
separações com fase móvel em pH menores que 10, a alumina tem aplicação muito similar à sílica, entretanto, colunas de alumina apresentam menor número de pratos do que colunas de sílica.

A alumina não modificada é bastante utilizada como fase normal para separação de solutos fracamente polares. Em fase reversa, a alumina pode ser utilizada tanto com ligações covalentes de cadeias alquilas na sua superfície ou através de recobrimento superficial com uma camada de polímero. Por outro lado, fases comerciais disponíveis com este suporte são muito limitadas.

A zirconia ${ }^{13,14,16-19}$, tanto porosa como não porosa, também está sendo utilizada como material de recheio ou suporte para CLAE, sendo que é quimicamente estável a $\mathrm{pH}$ extremos e temperaturas elevadas (maiores que $100^{\circ} \mathrm{C}$ ), além de possuir alta resistência mecânica. $\mathrm{O}$ grande problema da utilização da zircônia é que a sua superfície tem sítios que são classificados como ácidos fortes de Lewis. Estes sítios ácidos são promovidos por átomos de zircônio (IV) que não têm todas as suas ligações de coordenação completas e podem interagir com bases fortes de Lewis, como fosfatos, hidróxidos, fluoretos, e outros, produzindo picos com caudas ou até mesmo favorecendo adsorção irreversível. Para prevenir o efeito dos sítios ácidos sobre a superfície da zircônia, adicionam-se bases fortes de Lewis à fase móvel para competir com os grupos básicos do soluto, ou então pode-se modificar a sua superfície com fluoretos ou fosfatos.

A titânia ${ }^{14,16,20}$ tem as mesmas propriedades mecânicas da sílica, mas possui maior estabilidade química. É um óxido metálico anfótero que pode ser utilizado como trocador aniônico em $\mathrm{pH}$ ácido e trocador catiônico em pH alcalino. Em sua superfície existem os chamados grupos titanóis ácidos que, como a sílica, também adsorvem compostos básicos.

Como citado anteriormente a sílica ainda é o óxido mais utilizado como suporte em CLAE-FR e muitos estudos vêm sendo feitos para tentar melhorar a sua estabilidade em $\mathrm{pH}$ extremos. Uma possibilidade é a modificação da sua superfície, aproveitando as suas propriedades favoráveis, tais como rigidez e reprodutibilidade de tamanho de poro e de partícula. A modificação superficial da sílica cromatográfica com os óxidos de magnésio ${ }^{21}$, zircônio ${ }^{22,23}$ e titânio ${ }^{24-26}$ já foi relatada com resultados promissores, após a preparação de fases estacionárias com polímero adsorvido e imobilizado na sua superfície.

Outra possibilidade é a utilização de fases estacionárias híbridas com matriz orgânica-inorgânica. Estas fases são comercializadas pela Waters com o nome de X-Terra ${ }^{27,28}$ e são obtidas pela reação de um tetraalcoxissilano com um alquiltrialcoxissilano para formar um precursor, que é então utilizado para criar as partículas (reação 1):

$$
\begin{aligned}
(\mathrm{RO})_{4} \mathrm{Si}+\mathrm{n}(\mathrm{RO})_{3} \mathrm{SiR}^{\prime}+(1,5 \mathrm{n}+2) \mathrm{H}_{2} \mathrm{O} \rightarrow & \mathrm{SiO}_{2}\left(\mathrm{R}^{\prime} \mathrm{SiO}_{1,5}\right)_{\mathrm{n}} \\
+ & (3 \mathrm{n}+4) \mathrm{ROH}
\end{aligned}
$$

Como resultado final obtem-se uma partícula contendo unidades inorgânicas $\left(\mathrm{SiO}_{2}\right)$ e orgânicas $\left(\mathrm{R}^{\prime} \mathrm{SiO}_{1,5}\right)$, com o grupo alquila ( $\mathrm{R}^{\prime}$ ) incorporado na matriz. O uso de diferentes grupos alquilas, assim como diferentes proporções dos materiais de partida, foram investigados e o material com as melhores propriedades foi aquele com composição $\mathrm{SiO}_{2}\left(\mathrm{CH}_{3} \mathrm{SiO}_{1,5}\right)_{0,5}{ }^{27}$. As fases estacionárias quimicamente ligadas obtidas dos materiais híbridos, são mais estáveis que as fases quimicamente ligadas convencionais e também apresentam um menor número de grupos silanóis, devido ao maior recobrimento superficial pelos grupos alquilas.

\section{FASES REVERSAS}

Como as fases estacionárias para utilização como fase reversa devem apresentar carácter apolar e a superfície dos óxidos utilizados como suporte são polares, deve-se então introduzir grupos orgâni- cos apolares nas suas superfícies. Existem várias formas de se obter as camadas orgânicas apolares sobre a superfície dos diferentes óxidos. O método mais comum ocorre através da introdução de monocamadas orgânicas via reação com reagentes apropriados, produzindo as chamadas fases quimicamente ligadas. Outros envolvem o recobrimento superficial dos óxidos com polímeros orgânicos.

\section{FASES ESTACIONÁRIAS QUIMICAMENTE LIGADAS}

A modificação da superfície da sílica e dos óxidos metálicos com a introdução de uma camada quimicamente ligada ao suporte tem como objetivo principal unir, em um só material, as propriedades químicas dos grupos orgânicos com a rigidez e a estabilidade térmica e hidrolítica do óxido inorgânico.

Existem vários procedimentos descritos para a formação de uma camada quimicamente ligada sobre a superfície de óxidos. Dentre eles, os principais são: esterificação, cloração seguida de reação com reagente de Grignard ou composto organo-lítio, e organossilanização. Outros dois procedimentos de menor importância nos dias de hoje são: organossilanização catalisada por amônia e organossilanização em fase de vapor ${ }^{29,30}$. As reações mais importantes são descritas nos parágrafos a seguir.

A esterificação ${ }^{31}$ foi utilizada no passado para modificar a superfície da sílica e envolve a reação de um álcool com o grupo silanol superficial, como mostrado na reação 2 .

$\equiv \mathrm{Si}-\mathrm{OH}+\mathrm{ROH} \rightarrow \equiv \mathrm{Si}-\mathrm{OR}+\mathrm{H}_{2} \mathrm{O}$

Devido a simplicidade, este método foi o primeiro a ser utilizado para obter fases quimicamente ligadas. Entretanto, a ligação $\equiv \mathrm{Si}-\mathrm{O}-$ $\mathrm{C}$ é muito instável hidroliticamente e não pode ser utilizada com fases móveis aquosas ou alcoólicas. Por isso, estas fases foram rapidamente abandonadas.

A cloração seguida de reação com reagente de Grignard ou composto organo-lítio também foi empregada ${ }^{31}$ na modificação da sílica e consiste de uma etapa de cloração superficial com cloreto de tionila (reação 3), seguida pela ligação da cadeia alquila através de um reagente de Grignard (reação 4) ou um composto organo-lítio (reação 5).

$$
\begin{aligned}
& \equiv \mathrm{Si}-\mathrm{OH}+\mathrm{SOCl}_{2} \rightarrow \mathrm{Si}-\mathrm{Cl}+\mathrm{SO}_{2}+\mathrm{HCl} \\
& \equiv \mathrm{Si}-\mathrm{Cl}+\mathrm{BrMgR} \rightarrow \mathrm{Si}-\mathrm{R}+\mathrm{MgClBr} \\
& \equiv \mathrm{Si}-\mathrm{Cl}+\mathrm{LiR} \rightarrow \mathrm{Si}-\mathrm{R}+\mathrm{LiCl}
\end{aligned}
$$

A ligação $\equiv \mathrm{Si}$-C tem maior estabilidade que as ligações $\mathrm{Si}-\mathrm{O}-\mathrm{Si}$ $\mathrm{R}$, formada na reação de organossilanização (descrita a seguir), entretanto o uso do reagente de Grignard ou o composto organo-lítio na síntese torna este procedimento economicamente inviável e também foi abandonado rapidamente.

A organossilanização em condições anidras é o método mais utilizado atualmente para a modificação da superfície da sílica e dos óxidos metálicos ${ }^{17,29,31-35}$. Primeiramente, é necessário ativar os grupos hidroxilas da superfície do óxido através de aquecimento, removendo as moléculas de água ligadas à superfície do óxido por pontes de hidrogênio. Em seguida promove-se a reação entre um organossilano monofuncional e os grupos hidroxilas superficiais, como mostrado na reação 6 , onde $\mathrm{M}$ pode ser $\mathrm{Si}, \mathrm{Al}$, Ti ou $\mathrm{Zr}$. O agente silanizante é representado por $\mathrm{XSiR}_{2}{ }_{2} \mathrm{R}$, onde $\mathrm{X}$ representa o grupo funcional reativo que usualmente é um cloreto ou um grupo alcóxido (etoxi ou metoxi), $\mathrm{R}$ pode ser uma cadeia alifática ou uma cadeia alifática com grupos polares terminais, que se deseja introduzir no suporte e R' geralmente é um grupo metila. Em fase reversa $\mathrm{R}$ 
representa as cadeias C-8 e C-18, que são as mais utilizadas, sendo que cadeias de C-2 a C-30 são também encontradas ${ }^{36}$. Em fase normal, utiliza-se geralmente grupos terminais ciano ou amino ligados a uma cadeia alifática. As fases assim produzidas são comumente chamadas fases "tipo escova" ${ }^{37}$ ou fases "monoméricas" 38 .

$\mathrm{M}-\mathrm{OH}+\mathrm{XSiR}_{2}{ }_{2} \mathrm{R} \rightarrow \mathrm{M}-\mathrm{O}-\mathrm{SiR}_{2}{ }_{2} \mathrm{R}+\mathrm{HX}$

Reação similar, em condições anidras, também pode ser obtida utilizando reagentes difuncionais e trifuncionais, representados por $\mathrm{X}_{2} \mathrm{SiR}^{\prime} \mathrm{R}$ e $\mathrm{X}_{3} \mathrm{SiR}$, respectivamente, mas, neste caso, as condições da reação devem ser muito bem controladas, evitando principalmente a presença de água, que pode hidrolisar o agente silanizante, ocorrendo reações de condensação ou entrecruzamento entre os reagentes silanizantes. A reação pode acontecer entre um ou dois grupos hidroxilas do suporte, como mostrado nas reações 7 e 8 . Em uma etapa final, os grupos $\mathrm{X}$ residuais são hidrolizados, produzindo outros grupos $\equiv \mathrm{Si}-\mathrm{OH}$.

$\mathrm{M}-\mathrm{OH}+\mathrm{X}_{3} \mathrm{SiR} \rightarrow \mathrm{M}-\mathrm{O}-\mathrm{SiX}_{2} \mathrm{R}+\mathrm{HX}$

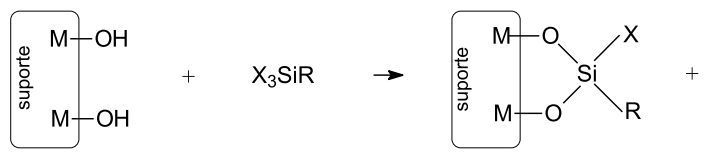

O grande problema das reações 6,7 e 8 é que não se consegue reagir todos os grupos hidroxilas superficiais, devido aos impedimentos estéricos. Para resolver este problema e eliminar os grupos hidroxilas residuais promove-se mais uma reação posterior de silanização com um reagente organossilano com cadeias laterais pequenas como o clorotrimetilsilano. Este procedimento é chamado de capeamento $^{39,40}$. Com o capeamento, consegue-se reduzir substancialmente o número de silanóis residuais, mas não totalmente. Apesar dos inconvenientes, as colunas obtidas com estas fases apresentam alta eficiência.

Outra forma de melhorar a estabilidade das fases estacionárias quimicamente ligadas é utilizar as chamadas fases estacionárias estericamente protegidas ${ }^{7,41}$. Neste tipo de fase estacionária o reagente organossilano, além de possuir a cadeia alquila lateral que se deseja introduzir na fase estacionária, também tem dois grupos alquilas volumosos como o isobutil, que promovem a proteção dos grupos silanóis (Figura 1). Neste caso obtem-se um menor recobrimento do
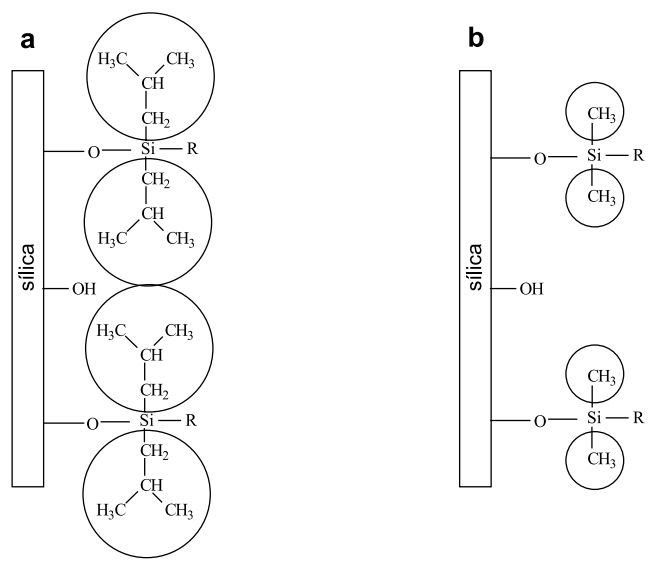

Figura 1. Fases estacionárias quimicamente ligadas: a) estericamente protegida por grupo volumoso e b) não protegida suporte devido a limitação estérica durante a reação de silanização, exibindo assim menor retenção dos solutos quando comparado com as fases estericamente não protegidas com mesma cadeia alquila lateral. Por outro lado, os silanóis são bem menos disponíveis para interagir com os solutos presentes na fase móvel, não necessitando reação de capeamento para obter uma fase estacionária capaz de separar os compostos básicos sem cauda.

Dentre as várias estruturas mostradas na literatura de fases estacionárias quimicamente ligadas, vêm se destacando aquelas provenientes de reagentes silanizantes contendo grupos polares inseridos no meio das cadeias alquilas, por exemplo, um reagente como $\mathrm{XSiR}_{2}\left(\mathrm{CH}_{2}\right)_{3} \mathrm{Y}\left(\mathrm{C}_{8} \mathrm{H}_{17}\right)$ ou $\mathrm{XSiR}_{2}\left(\mathrm{CH}_{2}\right)_{3} \mathrm{Y}\left(\mathrm{C}_{18} \mathrm{H}_{37}\right)$, sendo que $\mathrm{Y}$ representa grupos de amida, uréia, carbamato ou amina ${ }^{42-46}$. Estas fases exibem diferentes seletividades para analitos polares, são estáveis e reprodutíveis em fases móveis altamente aquosas e promovem picos bastante simétricos para compostos básicos ${ }^{47}$. Uma vantagem da utilização destas fases, em comparação com as fases que possuem somente cadeias alquilas, está relacionada com a necessidade de menor concentração de modificador orgânico na fase móvel. Com a presença do grupo polar na fase estacionária e dependendo do soluto que se deseja separar e das condições da fase móvel, o mecanismo de retenção pode ocorrer por partição, troca-iônica ou ainda interações dipolo-dipolo ${ }^{45,48}$.

O grande problema destas fases está relacionado com a sua baixa estabilidade em $\mathrm{pH}$ extremos, quando comparada com as fases que possuem somente cadeias alquilas longas. Para resolver este problema Kirkland e colaboradores desenvolveram uma fase estacionária com grupos carbamatos no meio da cadeia alquila e ainda estericamente protegidas com grupos isopropilas, como mostrado na Figura $2^{44}$.

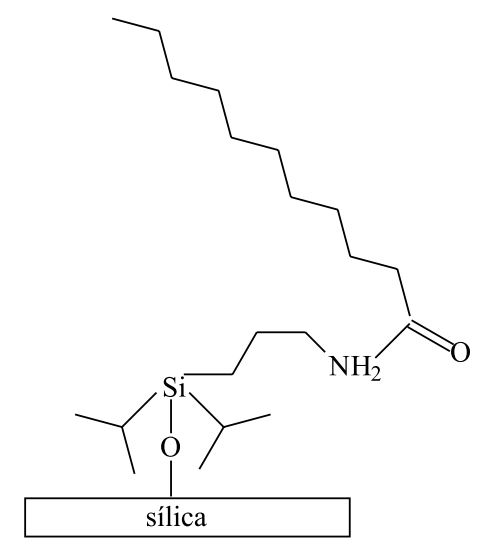

Figura 2. Estrutura da fase estacionária diisopropil-alquil-amida ${ }^{44}$

Fases estacionárias com cadeias alquilas quimicamente ligadas a zircônia $\left(\mathrm{ZrO}_{2}\right)^{13,14,16-19}$, titânia $\left(\mathrm{TiO}_{2}\right)^{14,16,49-52}$ e alumina $\left(\mathrm{Al}_{2} \mathrm{O}_{3}\right)^{13,14,15}$ também já foram preparadas e testadas. Os seus desempenhos são somente razoáveis, devido a problemas de reprodutibilidade na produção das partículas do suporte e no rendimento da reação de derivatização. A estabilidade hidrolítica da ligação Si-O-M das fases quimicamente ligadas, em relação à hidrólise, diminui na seguinte sequência de $\mathrm{M}: \mathrm{Si} \gg \mathrm{Ti} \sim \mathrm{Zr}$ 〉 Al. Devido a isso, o método mais promissor de modificar a superfície de alumina, titânia e zircônia é o recobrimento com um polímero ${ }^{53}$.

A reação de organossilanização na superfície do óxido também pode ser feita na presença de água ${ }^{29}$, utilizando reagentes silanizantes difuncionais ou trifuncionais. Neste caso, ocorre inicialmente uma préhidrólise do agente silanizante (reação 9), formando grupos silanóis, os quais posteriormente reagem com os grupos silanóis da molécula 
vizinha e também com os grupos hidroxilas da superfície do suporte (reação 10). Nesta reação se estabelecem as ligações do tipo siloxano ( $\equiv \mathrm{Si}-\mathrm{O}-\mathrm{Si} \equiv$ ) com a eliminação de água (condensação). Assim, o processo é constituído de reações do reagente silanizante em todas as direções, formando uma rede tridimensional sobre a superfície da sílica. Este tipo de fase estacionária quimicamente ligada é frequentemente chamada fase "polimérica" 38 . Além de serem mais espessas, as fases obtidas com este tipo de reação apresentam maior estabilidade hidrolítica em comparação com as fases produzidas na reação 6 .

$\mathrm{X}_{3} \mathrm{SiR}+3 \mathrm{H}_{2} \mathrm{O} \rightarrow \mathrm{RSi}(\mathrm{OH})_{3}+3 \mathrm{HX}$

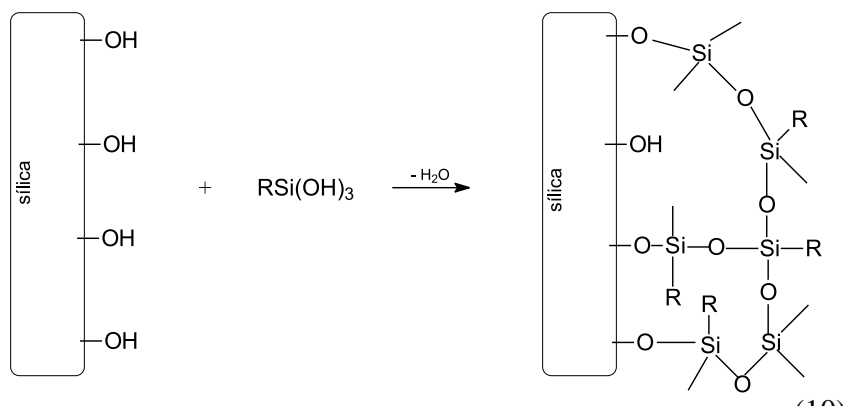

O maior problema encontrado neste processo é a dificuldade de se controlar a reação de entrecruzamento e a espessura da camada resultante, tornando o processo pouco reprodutível, sendo raramente formada uma camada uniforme sobre o suporte.

Um trabalho recente mostrou a preparação de uma fase reversa para CLAE, utilizando a reação de organossilanização na presença de água, constituída de polissiloxanos com cadeias alifáticas variadas (C-28 a C-42) sobre a superfície de sílica para a utilização na separação de carotenóides ${ }^{54}$.

Um novo conceito para a obtenção de monocamadas sobre partículas de sílica foi criado por Wirth e Fatunmbi ${ }^{55}$ nos últimos anos. O método é baseado na reação de silanos trifuncionais restrita à superfície do suporte.

O motivo do entrecruzamento restrito à direção horizontal está relacionado com a presença de água somente adsorvida na superfície do suporte durante a reação de organossilanização. Durante a reação, os reagentes trifuncionais são ligados um ao lado do outro e também à superfície da sílica, formando um filme ordenado e denso, denominado monocamada auto-organizada ("self-assembled monolayer"), como mostrado na reação 11 , onde R é um grupo pequeno, como o metil e R' é um grupo maior como C-8 ou C-18.

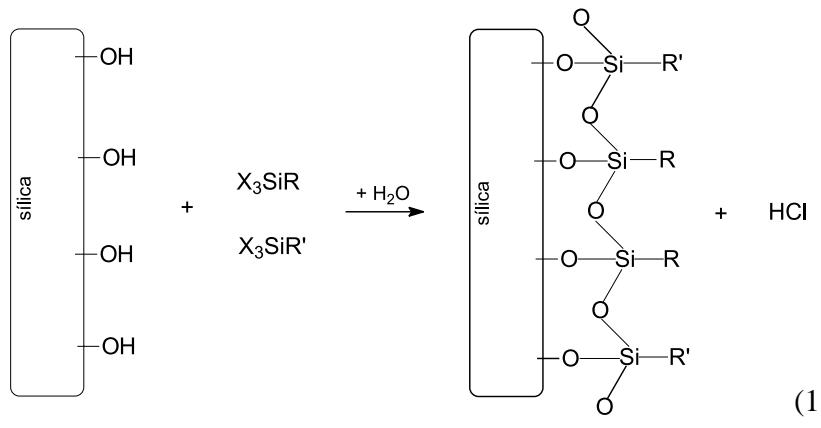

Este entrecruzamento horizontal difere do entrecruzamento por organossilanização convencional em dois aspectos: primeiro, a monocamada é obtida de uma mistura de reagentes triclorofuncionais, que leva a uma monocamada contendo uma pequena quantidade dos grupos maiores, promovendo uma seletividade parecida com a das fases monoméricas. Segundo, a polimerização usa a água intrinsecamente adsorvida na superfície da sílica. A quantidade de água utilizada neste método é muito menor e pode ser controlada reprodutivelmente ${ }^{56}$. Como não há água em solução, o entrecruzamento ocorre somente quando os reagentes entram em contato com a superfície do suporte. Assim, estas fases estacionárias mostraram alta estabilidade hidrolítica e baixa atividade dos grupos silanóis superficiais ${ }^{57}$.

Para evitar limitações estéricas durante a reação, promoveu-se o entrecruzamento horizontal com uma mistura de organossilanos trifuncionais com cadeias alifáticas $\mathrm{C} 1$ e C18 ${ }^{58}$ como mostrado na Figura 3. A mistura promoveu uma barreira sólida imediatamente sobre a superfície da sílica. A distribuição do grupo C-18 sobre a superfície é controlada pelos grupos C-1, que atuam como espaçadores, proporcionando melhor interação dispersiva entre as longas cadeias alifáticas e o soluto. A monocamada orientada também promove uma barreira entre a fase móvel e a superfície da sílica, impedindo a troca de prótons entre os silanóis residuais e a fase móvel e consequentemente reduzindo a formação de cargas superficiais. Estas fases foram submetidas a testes de estabilidade e se mostraram bastante resistentes tanto à fases móveis ácidas como básicas. A concentração dos grupos octadecil (C-18) pode ser ajustada variando a proporção dos reagentes organossilanos C-1 e C-18.

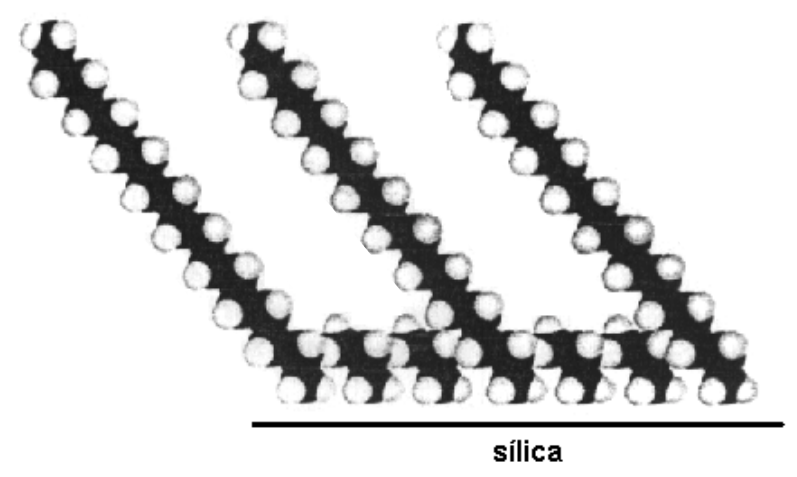

Figura 3. Representação esquemática da fase estacionária obtida pela polimerização horizontal de uma mistura de organossilanos com cadeias alifáticas $C-1$ e $C-18^{58}$

No início a maior dificuldade encontrada com este tipo de fase estacionária estava relacionada com a reprodutibilidade de sua obtenção. Isto foi resolvido pelo controle da umidade da superfície da sílica antes de iniciar a reação ${ }^{57}$. Estas fases já foram bastante caracterizadas por métodos físicos e químicos nos últimos anos, não restando nenhuma dúvida da formação desta estrutura de monocamada auto-organizada.

Outro método, denominado recobrimento com hidreto intermediário, produz uma monocamada superficial de polissiloxanos com cadeias laterais alquilas em duas etapas. Primeiramente uma monocamada superficial de polissiloxano com grupamentos hidretos ( $\equiv \mathrm{Si}-\mathrm{H})$ é produzida pela silanização da superfície do óxido inorgânico com o produto de hidrólise do trietoxissilano (TES) (reação 12). Logo após, hidrocarbonetos terminalmente insaturados, como o 1-octadeceno, são ligados ao polissiloxano na presença de um catalisador apropriado (reação 13).

Apesar da complexidade, este método produz um recobrimento de alta densidade de cadeias alquilas sobre o suporte, devido a pequena limitação estérica durante a reação de introdução destas cadeias sobre a superfície. Com a ligação $\equiv$ Si-C embutida, este recobrimento também proporciona uma alta estabilidade hidrolítica destas fases ${ }^{59}$. 


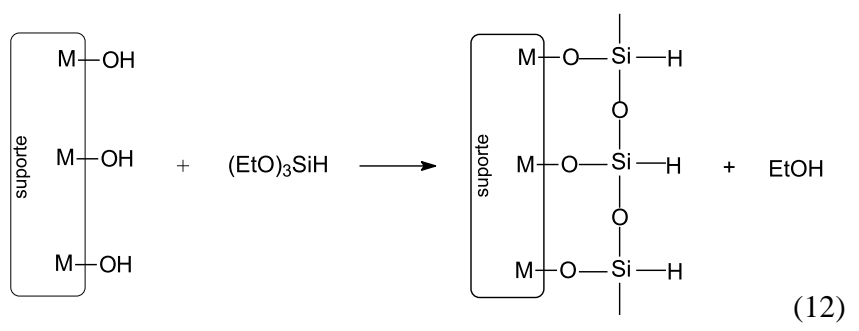

$\mathrm{M}-\mathrm{O}-\underset{\mathrm{Si}}{\mathrm{S}-\mathrm{H}}+\mathrm{CH}_{2}=\mathrm{CH}-\mathrm{R} \stackrel{\text { catalisador }}{\longrightarrow} \mathrm{M}-\mathrm{O}-\underset{\mid}{\mathrm{Si}}-\mathrm{CH}_{2}-\mathrm{CH}_{2}-\mathrm{R}$

A formação da monocamada com hidretos ( $\equiv \mathrm{Si}-\mathrm{H})$ sobre a superfície dos óxidos modificada com o TES é influenciada pela razão $\mathrm{TES} / \mathrm{OH}_{\text {superficial }}$ Quando esta razão for maior que 1 pode ocorrer uma maior polimerização do TES sobre a superfície, proporcionando o aparecimento de camadas mais espessas que podem interferir na eficiência cromatográfica ${ }^{60}$.

\section{FASES ESTACIONÁRIAS COM POLÍMEROS ADSORVIDOS E IMOBILIZADOS SOBRE O SUPORTE}

Nas últimas décadas, recobrimentos de suportes óxidos com polímeros têm se tornado um método de grande importância na preparação de fases estacionárias para CLAE-FR. Levando em consideração o desenvolvimento de fases estacionárias com camadas muito finas de polímeros (monocamadas), é óbvio que a diferença na velocidade de transferência de massa dos solutos nas fases modernas com polímeros e nas quimicamente ligadas estão ficando cada vez mais desprezíveis. A preparação destas fases estacionárias foi tão bem sucedida que atualmente inúmeras delas estão sendo comercializadas.

O objetivo de produzir fases com polímeros recobertos sobre um suporte é combinar a resistência mecânica da matriz inorgânica com a seletividade e inércia química dos polímeros orgânicos.

As principais vantagens das fases com polímeros sobre as quimicamente ligadas são: maior recobrimento dos sítios ativos do suporte e a possibilidade de maior seletividade da fase estacionária pela escolha do polímero apropriado. A seletividade é influenciada pela natureza e quantidade de grupos funcionais nas cadeias dos polímeros, pela espessura do filme polimérico e pela área superficial e estrutura de poros do suporte. A imensa variedade de polímeros orgânicos disponíveis possibilita preparar fases com uma grande faixa de seletividade.

A imobilização de polímeros sobre um suporte poroso é um processo complexo, influenciado pela contribuição dos diferentes tipos de interações entre o suporte e o polímero, entre as moléculas adjacentes na superfície do suporte e, também, pela solubilidade do polímero nas fases móveis. Não só as propriedades cromatográficas do compósito polímero-suporte mas também o processo de imobilização do polímero são influenciados pelas propriedades do suporte. Portanto, a escolha do suporte com propriedades adequadas é de fundamental importância na preparação das fases com polímeros.

Existem vários tipos de recobrimentos. Um dos mais comuns usados em cromatografia consiste da adsorção física de um polímero previamente sintetizado, com composição química bem definida, sobre o suporte. Alternativamente, o polímero também pode ser introduzido pela polimerização de monômeros in situ ${ }^{61}$. Pode ocorrer um processo posterior de imobilização por reticulação (ligações cruzadas), induzidas por peróxido ${ }^{62-66}$, tratamento térmico ${ }^{63,67,68}$, radiação ionizante- $\gamma^{61,62,69} \mathrm{e}$ outras, ou ainda promover a ligação covalente entre o polímero e o suporte, produzindo uma monocamada ancora$\mathrm{da}^{61}$. Neste último caso, o polímero deve apresentar grupos funcionais específicos ou reativos para se ligar ao suporte.

Entre os polímeros já utilizados estão o poli(etileno) ${ }^{70-71}$, o poli(butadieno) ${ }^{13,63,72-81}$, o poli(estireno $)^{82,83}$, o poli(dimetilsiloxano $)^{66}$, o poli(metiloctilsiloxano) ${ }^{61-63,67,69,84}$ e o poli(metiloctadecilsiloxano $)^{62,63}$. Também são utilizados poliéteres, polissacarídeos, poliaminas, polinucleotídeos, poliamidas e proteínas. Dentre os suportes utilizados na preparação de fases estacionárias com polímeros estão a sílica ${ }^{13,62,64,70-73,84-91}$, a zircônia ${ }^{13,17,70,71,76-83,92,93}$, a titânia ${ }^{81}$ e a alumina $^{14,64,66,74,75,92}$.

A forma mais simples de preparar o compósito suporte-polímero é pela deposição de uma camada polimérica sobre a superfície do suporte, sem promover a reticulação entre as cadeias do polímero e também sem a ligação química entre o polímero e o suporte. Neste caso ocorre uma contribuição de um ou mais tipos de interações como dipolo-dipolo, ligações de hidrogênio e interações eletrostáticas entre as cadeias do polímero e o suporte. A insolubilidade do polímero na fase móvel também é importante neste tipo de fase.

Duas formas, bem diferentes, são as mais utilizadas para colocar o polímero sobre o suporte. Na primeira, mistura-se o polímero em solução com o suporte e posteriormente evapora-se o solvente e, na segunda, promove-se a polimerização in situ de monômeros sobre o suporte. A espessura do recobrimento nos dois casos pode ser controlada pela quantidade de polímero ou monômero no processo de deposição.

Mao e Fung ${ }^{66}$ obtiveram uma fase reversa para CLAE pela copolimerização in situ de ácido maleico e 1-octadeceno sobre a supefície de alumina. O copolímero foi reticulado com 1,4divinilbenzeno. A interação do ácido carboxílico sobre a superfície da alumina é muito forte, ocorrendo um ancoramento do filme polimérico pela formação de duas pontes de hidrogênio fortes com a superfície para cada grupo carboxílico do polímero. A monocamada resultante propiciou estabilidade química à fase estacionária tanto em meio ácido como básico.

Li et al. ${ }^{94}$ estudaram os fatores que influenciam a deposição de polibutadieno (PBD) sobre zircônia porosa. Eles utilizaram peróxido de dicumila como agente de reticulação do polímero. Foi mostrado que o processo de deposição do polímero é influenciado pela velocidade de evaporação do solvente da solução, pela afinidade do polímero pela superfície do suporte e pela interação polímerosolvente. Em outro estudo ${ }^{95}$ comparou-se a adsorção do PBD, também reticulado com peróxido de dicumila sobre sílica, alumina ou zircônia, e concluiu-se que estas fases apresentam comportamentos cromatográficos similares, embora a fase baseada em zircônia apresente sítios ácidos fortes de Lewis que não são protegidos pelo recobrimento.

Fases estacionárias para a separação de isômeros foram obtidas pela adsorção de polivinilamina ${ }^{96,97}$ ou o copolímero de vinilamina/ álcool vinílico ${ }^{98}$, reticulados sobre sílica. Após a reticulação foram introduzidas ciclodextrinas quimicamente ligadas às cadeias do polímero para promoverem a separação dos isômeros geométricos.

Recentes trabalhos em nosso Laboratório de Pesquisas em Cromatografia Líquida (LABCROM) utilizaram líquidos poliméricos, tais como o poli(metiloctilsiloxano) (PMOS) ou o poli(metiloctadecilsiloxano) (PMODS), que se encontram adsorvidos, isto é, depositados, dentro dos poros da sílica cromatográfica nua. As fases estacionárias preparadas utilizando este método apresentaram propriedades cromatográficas similares às colunas comerciais recheadas com fases estacionárias contendo os mesmos grupos alquilas ${ }^{85-89}$.

Entre os resultados interessantes obtidos nesta pesquisa, um estudo da distribuição do PMOS líquido nos poros, quando os poros não estão cheios, indicou que ela não é uniforme; o líquido encon- 
tra-se preferencialmente distribuído em gotas ou "plugs" tribuição é explicada como resultado do fenômeno de "instabilidade de Raleigh" no qual é energeticamente desfavorável para um líquido atingir uma configuração em uma grande área, tal como uma camada fina depositada na superfície dos poros da sílica, quando existe a opção da formação de "plugs" "86. Quando uma certa quantidade do PMOS é sorvida nos poros da sílica como "plugs" e, depois de um certo período de repouso, as partículas de sílica contendo este líquido são submetidas a uma extração com um solvente forte, tal como $\mathrm{CH}_{2} \mathrm{Cl}_{2}$, somente uma porção do polímero é extraída, a restante está seguramente fixa nos poros ${ }^{85,99}$. Desde que o polímero livre é muito solúvel neste solvente, os resultados indicam que uma porção do polímero torna-se firmemente adsorvida, isto é, auto-imobilizada, com fortes atrações à superfície do suporte, de uma maneira útil para fins cromatográficos ${ }^{99}$. A adsorção ocorre em muitos pontos de contato entre a superfície da sílica e a molécula longa (linear) do polissiloxano ${ }^{100}$. Isto leva a um novo modelo desta fase estacionária com o polímero adsorvido, onde o esqueleto de siloxano está espalhado dentro dos poros, acima da superfície da sílica, com os grupos octil estendidos para o centro do poro ${ }^{90}$. Sendo assim, a estrutura da fase estacionária de PMOS adsorvido é formalmente similar à estrutura das fases estacionárias convencionais quimicamente ligadas, com os grupos octil estendidos para o centro do poro. Por outro lado, a estrutura da monocamada da fase estacionária quimicamente ligada tem um aspecto diferente desta estrutura, ou seja, a distribuição dos grupos alquilas é de baixo grau de organização na superfície, sendo que a reação de derivatização tem um rendimento que implica em reação com, no máximo, 30 a $45 \%$ dos grupos silanóis disponíveis ${ }^{101}$, dando um caráter não regular à superfície da sílica amorfa derivatizada. No caso do espalhamento das moléculas longas de PMOS (ou outro polímero com estrutura linear), os grupos alquil estão localizados, com regularidade, na cadeia do siloxano e existe um alto grau de organização inerente no sentido compacto ao longo do esqueleto da molécula. Isto deve ser refletido em propriedades físicas e cromatográficas diferentes, potencialmente favoráveis, para o caso das fases preparadas com polissiloxanos.

Outros trabalhos realizados no LABCROM envolvem a utilização de sílicas com suas superfícies modificadas. Sílica, após a reação com tetrabutóxido de zircônio, resulta em sílica zirconizada ( $\equiv \mathrm{Si}$ $\left.\mathrm{O}-\mathrm{ZrO}_{\mathrm{x}}\right)^{22,23}$, enquanto a reação de sílica com tetrabutóxido de titânio ou tetracloreto de titânio produz sílica titanizada $\left(\equiv \mathrm{Si}-\mathrm{O}-\mathrm{TiO}_{\mathrm{x}}\right)^{24-26}$. Estes dois novos suportes foram recobertos com PMOS pelo método de evaporação do solvente. Os resultados indicam que a adsorção encontrada com a sílica nua, isto é, a atração forte entre o polímero e a superfície ${ }^{99}$, não é obtida com os suportes de sílica modificada com zircônio ou titânia e o líquido polimérico se arrasta lentamente com a passagem da fase móvel. Por outro lado, a imobilização por radiação gama ${ }^{22-26}$, mostrou-se muito efetiva com os suportes de sílica com superfícies modificadas. Testes de estabilidade destas fases estacionárias, feitos pela passagem de volumes controlados de fase móvel, indicam que as fases estacionárias com PMOS imobilizado por radiação gama sobre a superfície da sílica zirconizada ${ }^{23}$ ou a sílica titanizada ${ }^{25}$ apresentam estabilidade cromatográfica igual ou melhor que as fases comerciais quimicamente ligadas.

Um resultado significativo obtido com estas fases estacionárias preparadas com as sílicas modificadas, com uma camada de PMOS imobilizada sobre as suas superfícies, é a sua estabilidade frente às fases móveis de $\mathrm{pH}$ elevado. Utilizando o desempenho cromatográfico como ferramenta de avaliação, não foi observado comportamento que indicasse degradação da sílica derivatizada com a passagem de volumes significativos de fases móveis básicas. Isto sugere que uma aplicação destas fases estacionárias seria na separação de compostos básicos utilizando fases móveis de $\mathrm{pH}$ elevado ${ }^{23,25}$.
Outra forma de melhorar a estabilidade da fase estacionária é promovendo o ancoramento (ligação química) do polímero sobre o suporte. A ligação química entre o recobrimento polimérico e o suporte pode ocorrer de duas formas diferentes. Na primeira, uma reação de ligação é induzida após a deposição do polímero sobre o suporte ${ }^{102,103}$. Neste caso deve haver grupos reativos específicos no polímero e no suporte para ocorrer a ligação covalente, caso isso não ocorra, deve-se introduzí-los. Na segunda, a ligação ocorre no momento da polimerização de monômeros sobre o suporte. Um exemplo deste procedimento é a reação de organossilanização na presença de água, descrita previamente ${ }^{55-57}$.

São poucas as fases com polímeros quimicamente ligados ao suporte mostradas na literatura. Duas delas foram preparadas para utilização como fase reversa e foram obtidas pelo recobrimento de sílica com copolímeros baseados em vinilmetildietoxissilano ${ }^{102,103}$. Os copolímeros foram ligados à superfície da sílica através de ligações covalentes entre os grupos silanóis da sílica e o grupo etoxisilil dos copolímeros.

Novas fases reversas para CLAE também estão sendo desenvolvidas baseadas no recobrimento da superfície da sílica com líquidos cristalinos de baixa ou de alta massa molar. Líquidos cristalinos representam um estado da matéria intermediário entre um sólido cristalino e um líquido isotrópico.

A imobilização destes líquidos cristalinos sobre o suporte pode ser feita de várias formas, dependendo dos grupos funcionais presentes nestes compostos. A imobilização mais frequente é feita pela ligação química do suporte com um reagente clorossilano modificado com o líquido cristalino, promovendo uma monocamada ${ }^{104}$. O método de hidreto intermediário também é muito utilizado para a imobilização dos líquidos cristalinos de baixa ou de alta massa molar ${ }^{105}$.

Delaurent e colaboradores ${ }^{106}$ produziram e caracterizaram uma fase estacionária constituída de cloroformato colestérico quimicamente ligado a aminopropil sílica através de uma ligação carbamato. Esta fase se mostrou bastante eficiente na separação de hidrocarbonetos aromáticos e também apresentou seletividade diferente das fases monoméricas $\mathrm{C}-18$ convencionais.

Mais recentemente um trabalho mostrou a configuração de quatro fases estacionárias diferentes com o mesmo líquido cristalino ${ }^{104}$. As duas primeiras fases foram obtidas pela ligação química do líquido cristalino "longitudinalmente" e "lateralmente" à superfície da sílica (Figura 4). Nas outras duas, o líquido cristalino foi ligado "longitudinalmente" e "lateralmente" a um polissiloxano (Figura 5) que posteriormente foi depositado sobre a superfície da sílica pelo método de evaporação do solvente.

Foi mostrado que a seletividade destas fases estacionárias são altamente dependentes da forma do líquido cristalino. Entre as fases estudadas, aquelas com o líquido cristalino fixado "lateralmente" ao polissiloxano apresentaram o melhor desempenho cromatográfico na separação de hidrocarbonetos aromáticos.

Um novo conceito de obtenção de fases estacionárias baseadas na combinação da técnica de adsorção polimérica sobre um suporte com o conceito de mistura funcional foi proposta por Kanda e colaboradores ${ }^{107,108}$. Estas fases são constituídas de grupos hidrofílicos intercalados com grupos hidrofóbicos presos a uma mesma monocamada de polímero depositada sobre a superfície da sílica. Estas fases foram preparadas com o objetivo de serem utilizadas na análise direta de fluídos biológicos.

Para a preparação destas fases, primeiro deposita-se uma monocamada de polissiloxano através de reação de grupos hidretos (Si-H) sobre a superfície do suporte e, posteriormente, introduz-se os grupos hidrofóbicos (metil, fenil e octadecil) e hidrofílicos (polioxietileno) na cadeia polimérica através de reação com um alqueno terminal, com auxílio de um catalizador apropriado (reação 14). 


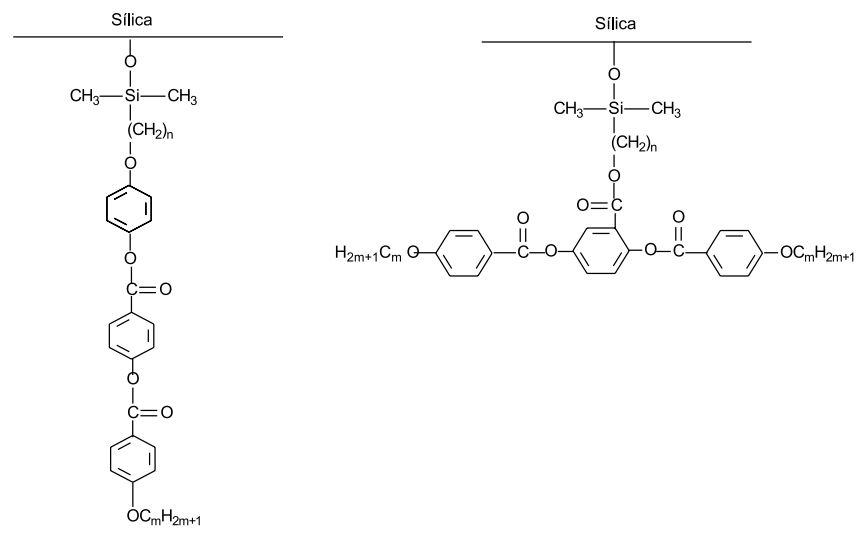

Figura 4. Líquido cristalino ligado longitudinalmente e lateralmente à superfície da sílica

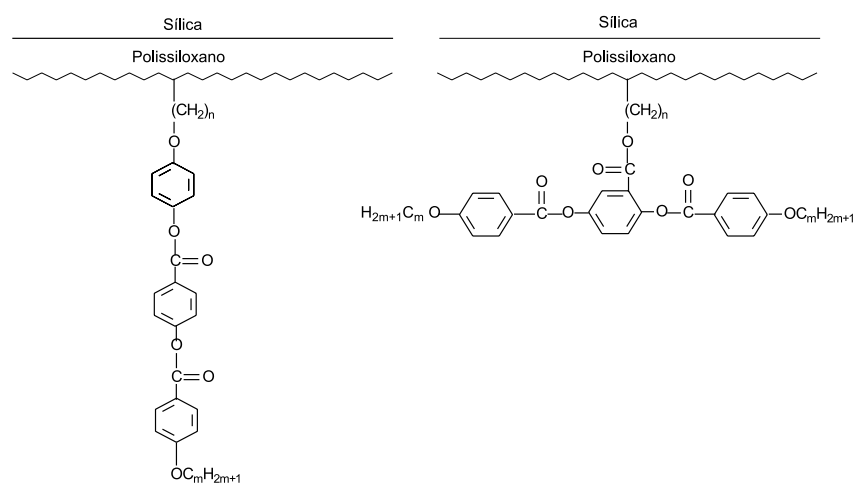

Figura 5. Líquido cristalino ligado longitudinalmente e lateralmente ao polissiloxano

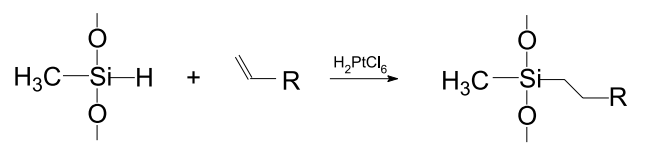

Três exemplos destas fases estacionárias são mostrados na Figura $6^{108}$, onde o grupo hidrofílico para todas é o polioxietileno e os grupos hidrofóbicos são o metil, octil e fenil.

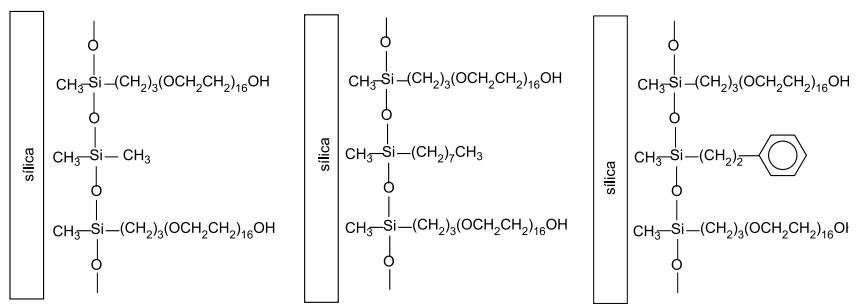

Figura 6. Representação esquemática de três fases estacionárias obtidas pela deposição de um polímero com mistura funcional ${ }^{108}$

\section{FASES ESTACIONÁRIAS MONOLÍTICAS}

Fases estacionárias baseadas em sílica monolítica ou monolitos de polímeros estão sendo muito estudadas atualmente e são de grande interesse em CLAE. As colunas monolíticas diferem dos materiais convencionais de enchimento, sendo que são uma única estrutura porosa com macroporos e mesoporos em um único sólido, em com- paração com um leito de partículas convencionais. Por apresentarem uma estrutura com muitos macroporos, estes monolitos permitem alta permeabilidade da fase móvel, podendo serem utilizados com altas vazões de fase móvel sem atingir altas pressões, enquanto nos mesoporos ocorrem as separações. As colunas obtidas com estas fases não necessitam de filtros nas extremidades, eliminando assim, o espalhamento da banda proveniente deste acessório da coluna. A primeira coluna comercial contendo fase estacionária monolítica baseada em sílica foi a Chromolith, da Merck, contendo grupos C18 quimicamente ligado nos mesoporos do monolito de silica dentro da coluna. Estas fases estão sendo pesquisadas principalmente para a chamada cromatografia rápida, mas também apresentam vantagens para a eletrocromatografia capilar e $\mu$-CLAE ${ }^{109-111}$.

\section{CONCLUSÕES}

Neste trabalho foi descrito um grande número de fases com as mais diversas estruturas. Não existe fase estacionária ideal, todas apresentam as suas vantagens e desvantagens. De um modo geral, as fases estacionárias quimicamente ligadas do tipo monoméricas produzem colunas com maior eficiência, sendo que são monocamadas verdadeiras. As fases quimicamente ligadas do tipo poliméricas promovem colunas mais estáveis às condições variadas de fases móveis e com maiores seletividades, pois promovem um melhor recobrimento dos suportes.

A fase estacionária ideal é aquela que une a mínima espessura do recobrimento com a máxima proteção superficial do suporte. As fases que mais se aproximam deste ideal são aquelas obtidas pelo processo de entrecruzamento horizontal e pelo método de hidreto intermediário, bem como as produzidas pela adsorção/imobilização de polímeros pré-formados sobre os diferentes óxidos inorgânicos.

A sílica ainda é o óxido mais utilizado como suporte para os mais diversos tipos de recobrimentos. Nos recobrimentos obtidos por ligação química, isto está relacionado com a maior estabilidade hidrolítica das ligações dos tipos $\equiv \mathrm{Si}-\mathrm{O}-\mathrm{Si} \equiv$ ou $\equiv \mathrm{Si}-\mathrm{C}$ com o suporte de sílica. Mas, para o recobrimento com polímeros pré-formados ou preparados in situ, a sílica só prevalece pela sua grande variedade comercial, pois a sílica metalizada e os demais óxidos apresentam propriedades físico-químicas até mais apropriadas que a sílica para este fim.

Avanços futuros de monocamadas sobre óxidos para utilização como fase estacionária em cromatografia líquida poderão aparecer de novas fases que apresentem polímeros pré-formados, imobilizados na superfície do suporte. Esta previsão é baseada na grande variedade de polímeros disponíveis, que poderão fornecer fases com variadas seletividades, diferentes processos de imobilização, estruturas químicas diversas (hidrofóbicas, hidrofílicas, carregadas, etc.), propriedades mecânicas adequadas e outras. As fases monolíticas também são bastante promissoras e podem vir a substituir os recheios cromatográficos convencionais constituídos de pequenas partículas, especialmente para a CLAE-FR em colunas "microbore" ou capilar, bem como na eletrocromatografia capilar.

\section{REFERÊNCIAS}

1. Majors, R. E.; LC-GC Special Issue on Current Issues in HPLC Technology, May 1997, S8.

2. Berthod, A.; J. Chromatogr., A 1991, 549, 1.

3. Nahum, A.; Horváth, C.; J. Chromatogr. 1981, 203, 53.

4. Nawrocki, J.; J. Chromatogr., A 1997, 779, 29.

5. Unger, K. K.; Porous Silica: its Properties and Use as Support in Column Liquid Chromatography, Elsevier: Amsterdam, 1979.

6. Scott, R. P. W.; Silica Gel and Bonded Phases: their Products, Properties and Use in Liquid Chromatography, Wiley: Chichester, 1993.

7. Kirkland, J. J.; Dilks, J. C. H.; Henderson, J. W.; LC-GC 1993, 11, 290.

8. Kirkland, J. J.; van Straten, M. A.; J. Chromatogr., A 1995, 691, 3.

9. Kirkland, J. J.; J. Chromatogr. Sci. 1996, 34, 309. 
10. Kirkland, J. J.; Henderson, J. W.; DeStefano, J. J.; van Straten, M. A.; Claessens, H. A.; J. Chromatogr., A 1997, 762, 97.

11. McCalley, D. V.; J. Chromatogr., A 1996, 738, 169.

12. Majors, R. E.; $L C-G C$ 2000, $18,586$.

13. Kurganov, A.; Davankov, V.; Isajeva, T.; Unger, K. K.; Eisenbeiss, F.; $J$. Chromatogr., A 1994, 660, 97.

14. Pesek, J. J.; Tang, V. H.; Chromatographia 1994, 39, 649.

15. Pesek, J. J.; Sandoval, J. E.; Su, M.; J. Chromatogr. 1993, 630, 95.

16. Trüdinger, U.; Müller, G.; Unger, K. K.; J. Chromatogr. 1990, 535, 111.

17. Yu, J.; El Rassi, Z.; J. Chromatogr., A 1993, 631, 91.

18. Yu, J.; El Rassi, Z.; J. Liq. Chromatogr. 1993, 16, 2931.

19. Wirth, H. J.; Eriksson, K. O.; Holt, P.; Aguilar, M.; Hearn, M. T. W.; J. Chromatogr. 1993, 646, 129.

20. Murayama, K.; Nakamura, H.; Takahashi, K.; Yoshida, A.; Anal. Sci. 1994, $10,815$.

21. Nobuhara, K.; Kato, M.; Nakamura, M.; Takami, M.; Kaneko, S.; J. Chromatogr., A 1995, 704, 45.

22. Melo, L. F. C.; Jardim, I. C. S. F.; J. Chromatogr., A 1999, 845, 423.

23. Melo, L. F. C.; Collins, C. H.; Collins, K. E.; Jardim, I. C. S. F.; J. Chromatogr., A 2000, 869, 129.

24. Silva, R. B.; Collins, C. H.; J. Chromatogr., A 1999, 845, 417.

25. Silva, R. B.; Collins, K. E.; Collins, C. H.; J. Chromatogr., A 2000, 869, 137.

26. Silva, R. B.; Gushikem, Y.; Collins, C. H.; J. Sep. Sci. 2001, 24, 49.

27. Neue, U. D.; Walter, T. H.; Alden, B. A.; Jiang, Z.; Fisk, R. P.; Cook, J. T.; Glose, K. H.; Carmody, J. L.; Grassi, J. M.; Cheng, Y. F.; Lu, Z.; Crowley, R. J.; Am. Lab. 1999, 31, 36.

28. Cheng, Y. F.; Walter, T. H.; Lu, Z.; Iraneta, P.; Alden, B. A.; Gendreau, C.; Grassi, J. M.; Carmody, J. L.; O'Gara, J. E.; Fisk, R. P.; LC-GC 2000, 18, 1162.

29. Vansant, E. F.; Van Der Voort D.; Vrancken C.; Characterization and Chemical Modification of the Silica Surface, Elsevier: New York, 1995.

30. Van der Voort, P.; Vansant, E. F.; J. Liq. Chromatogr. Relat. Technol. 1996, 19, 2723.

31. Pesek, J. J.; Matyska, M. T.; Sandoval, J. E.; Williamsen, E. J.; J. Liq. Chromatogr. Relat. Technol. 1996, 19, 2843.

32. Tani, K.; Suzuki, Y.; J. Liq. Chromatogr. Relat. Technol. 1996, 19, 3037.

33. Tani, K.; Suzuki, Y.; J. Chromatog., A 1996, 722, 129.

34. Sander, L. C.; Wise S. A.; Anal. Chem. 1995, 67, 3284.

35. Sander, L. C.; Pursch M.; Wise S. A.; Anal. Chem. 1999, 71, 4821.

36. Engelhardt, H.; Orth, P.; J. Liq. Chromatogr. 1987, 10, 1999.

37. Scott, R. P. W.; Simpson, C. F.; J. Chromatogr. Sci. 1992, 30, 59.

38. Sander, L. C.; Wise, S. A.; Crit. Rev. Anal. Chem. 1987, 18, 299.

39. Majors, R. E.; $L C$-GC 1994, 12, 508.

40. Sudo, A.; Wada, T; J. Chromatogr., A 1998, 813, 239.

41. Kirkland, J. J.; Glajch, J. L.; Farlee, R. D.; Anal. Chem. 1989, 61, 2.

42. O'Gara, J. E.; Alden, B. A.; Walter, T. H.; Petersen, J. S.; Niederlaender, C. L.; Neue, U. D.; Anal. Chem. 1995, 67, 3908.

43. Czajkowska, T.; Jaroniec, M.; J Chromatogr., A. 1997, 762, 147.

44. Kirkland, J. J.; Henderson, J. W.; Martosella, J. D.; Bidlingmeyer, B. A.; Vasta-Russel, J.; Adams, Jr. J. B.; LC-GC 1999, 17, 634.

45. Buszewski, B.; Gadzala-Kopciuch, R. M.; Markuszweski, M.; Kaliszan, R.; Anal. Chem. 1997, 69, 3277.

46. Silva, C. R; Jardim, I. C. S. F.; Airoldi, C.; J. Chromatogr., A, 2001, 913, 65 .

47. Majors, R. E.; $L C-G C$ 1998, 16, 228.

48. Czajkowska, T.; Jaroniec, M.; J. Liq. Chromatogr. Relat. Technol. 1996, 19, 2829.

49. Tani, K.; Suzuki, Y.; J. Chromatogr., A 1996, 722, 129.

50. Tani, K.; Suzuki, Y.; J. Liq. Chromatogr. Relat. Technol. 1996, 19, 3037.

51. Pesek, J. J.; Matyska, M.T.; Ramakrishnan, J.; Chromatographia 1997, 44, 538.

52. Murayama, K.; Nakamura, H.; Takahashi, K.; Yoshida, A.; Anal. Sci. 1994, 10,815 .

53. Kurganov, A.; Trüdinger, U.; Isaeva, T.; Unger, K.; Chromatographia 1996, 42, 217.

54. Bell, C. M.; Sander, L. C.; Fetzer, J. C.; Wise, S. A.; J. Chromatogr., A 1996, $753,37$.

55. Wirth, M. J.; Fatunmbi, H.O.; Anal. Chem. 1992, 64, 2783.

56. Wirth, M. J.; Fatunmbi, H. O.; J. Liq. Chromatogr. Relat. Technol. 1996, 19, 2799.

57. Fairbank, R. W. P.; Wirth, M. J.; J. Chromatogr., A 1999, 830, 285.

58. Akapo, S. O.; Fatunmbi, H. O.; $L C$-GC 1999, 17, 334.

59. Pesek, J. J.; Matyska, M. T.; Ramakrishnan, J.; Chromatographia 1997, 44, 538.

60. Pesek, J. J.; Tang, V. H.; Chromatographia 1994, 39, 649.

61. Schomburg, G.; Trends Anal. Chem. 1991, 10, 163.
62. Schomburg, G.; Deege, A.; Köhler, J.; Bien-Vogelsang, U.; J. Chromatogr. 1983, 282, 27.

63. Bien-Vogelsang, U.; Deege, A.; Figge, H.; Köhler, J.; Schomburg, G.; Chromatographia 1984, 19, 170

64. Hansen, M.; Unger, K. K.; Trends Anal. Chem. 1992, 11, 368.

65. Petro, M.; Berek, D.; Chromatographia 1993, 37, 561.

66. Mao, Y.; Fung, B.M.; J. Chromatogr., A 1997, 790, 9.

67. Nyholm, L. M.; Markides, K. E.; J. Chromatogr., A 1998, 813, 11.

68. Collins, K. E.; Sá A. L. A.; Bottoli, C. B. G.; Collins, C. H.; Chromatographia 2001, 53, 661 .

69. Figge, H.; Deege, A.; Köhler, J.; Schomburg, G.; J. Chromatogr. 1986, 351, 393.

70. Lecourtier, J.; Audebert, R.; Ouivovon, C.; J. Liq. Chromatogr. 1978, 1, 367.

71. Nasal, A.; Haber, P.; Kaliszan, R.; Forgács, E.; Cserháti, T.; Chromatographia 1996, 43, 484.

72. Forgács, E.; Cserháti, T.; J. Chromatogr., A 1998, 797, 33.

73. Hanson, M.; Unger, K. K.; Schomburg, G.; J. Chromatogr. 1990, 517, 269.

74. Haky, J. E.; Rayham, A.; Dunn, B. M.; J. Chromatogr 1991, 541, 303.

75. Garbow, J. R.; Asrar, J.; Hardiman, C. J.; Chem. Mater. 1993, 5, 869.

76. Hanggi, D. A.; Marks, N. R.; LC-GC 1993,11, 128.

77. Li, J.; Carr, P. W.; Anal. Chem. 1996, 68, 2857.

78. Li, J.; Carr, P.W.; Anal. Chem. Acta 1996, 334, 239.

79. Li, J.; Carr, P.W.; Anal. Chem. 1997, 69, 2202.

80. Reeder, D. H.; Li, J.; Carr, P.W.; Flickinger, M. C.; McCormick, V.; J. Chromatogr., A 1997, 760, 71.

81. Li, J.; Reeder, D. H.; McCormick, A. V.; Carr, P. W.; J. Chromatogr., A 1997, 791, 45

82. Kurganov, A.; Trüdinger, U.; Isaeva, T.; Unger, K. K.; Chromatographia 1996, 42, 217.

83. Zhao, J.; Carr, P. W.; Anal. Chem. 2000, 72, 302.

84. Schomburg, G.; Köhler, J.; Figge, H.; Deege, A.; Bien-Vogelsang, U.; Chromatographia 1984, 18, 265.

85. Anazawa, T. A.; Jardim, I.C.S.F.; J. Liq. Chromatogr. 1994, 17, 1265.

86. Collins, K. E.; Granja, M. L. M. M.; Pereira Filho, R. G.; Anazawa, T. A.; Jardim, I.C.S.F.; Chromatographia 1997, 45, 99.

87. Anazawa, T. A.; Carraro, F.; Collins, K. E.; Jardim, I.C.S.F.; J. Chromatogr., A 1995, 697, 159.

88. Anazawa, T. A.; Jardim, I.C.S.F.; J. Liq. Chromatogr. 1998, 21, 645.

89. Silva, M. C. H.; Jardim, I. C. S. F.; J. Liq. Chromatogr. Relat. Technol. 1998, 21, 2447.

90. Jardim, I. C. S. F.; Collins, K. E.; Anazawa, T. A.; J. Chromatogr., A 1999, 849, 299.

91. Hanson, M.; Kurganov, A.; Unger, K. K.; Davankov, V. A.; J. Chromatogr. 1993, 656, 369.

92. Castells, C. B.; Carr, P. W.; Anal. Chem. 1999, 71, 3013.

93. Zhao, J.; Carr, P. W.; Anal. Chem. 1999, 71, 5217.

94. Li, J.; Reeder, D. H.; McCormick, A. V.; Carr, P. W.; J. Chromatogr., A 1997, 791, 45

95. Sun, L.; McCormick, A. V.; e Carr, P. W., J. Chromatogr., A 1994, 658, 465.

96. Crini, G.; Morcellet, M.; J. Chromatogr. Sci. 1996, 34, 477.

97. Crini, G.; Morcellet, M.; J. Chromatogr. Sci. 1996, 34, 485.

98. Crini, G.; Lekchiri, Y.; Janus, L.; Morcellet, M.; Morin, N.; Chromatographia 1999, 50, 661 .

99. Collins, K. E.; Bottoli, C. B. G.; Bachmann, S.; Vigna, C. R. M.; Collins, C. H.; Albert, K.; Chem. Mat., no prelo.

100. Bachmann, S.; Melo, L. F. C.; Silva, R. B.; Anazawa, T. A.; Jardim, I. C. S. F.; Collins, K. E.; Collins, C. H.; Albert, K.; Chem. Mat. 2001, 13, 1874.

101. Kirkland, J. J.; LC-GC Current Issues in HPLC Technology, May 1997, S46.

102. Kurganov, A.; Puchkova, Y.; Davankov, V; Eisenbeiss, F.; J. Chromatogr., A 1994, 663, 163.

103. Kataev, A. D.; Saburov, V. V.; Reznikova, O. A.; Kapustin, D. V.; Zubov, V. P.; J. Chromatogr., A 1994, 660, 131.

104. Terrien, I.; Achard, M. F.; Félix, G.; Hardouin, F.; J. Chromatogr., A 1998, $810,19$.

105. Pesek, J. J.; Matyska, M. T.; Williamsen, E. J.; Tam, R.; Chromatographia 1995, 41, 301.

106. Delaurent, C.; Tomao, V.; Siouffi, A. M.; Chromatographia 1997, 45, 355.

107. Kanda, T.; Kutsuna, H.; Ohtsu, Y; Yamagushi, M.; J. Chromatog., A 1994, $672,51$.

108. Kanda, T.; Shirota O.; Ohtsu, Y.; Yamagushi, M.; J. Chromatog., A 1996, $722,115$.

109. Cabrera, K.; Wieland, G.; Lubda, D.; Nakanishi, K.; Soga N.; Minakushi, H.; Unger, K. K.; Trends Anal. Chem. 1998, 17, 50.

110. Meyers, J. J.; Liapis, A. I.; J. Chromatogr., A 1998, 827, 197.

111. Liapis, A. I.; Meyers, J. J.; Crosser, O. K.; J. Chromatogr., A 1999, 852, 3. 